\title{
Independent Correlation Between Ki67 Index and Circulating Tumor Cells in the Diagnosis of Colorectal Cancer
}

\author{
YINGCHI YANG, JUN LI, LAN JIN, DONG WANG, JINGHUI ZHANG, JIN WANG, \\ XIAOMU ZHAO, GUOCONG WU, HONGWEI YAO and ZHONGTAO ZHANG \\ Department of General Surgery, Beijing Key Laboratory of Cancer Invasion and Metastasis Research \\ \& National Clinical Research Center for Digestive Diseases, Beijing Friendship Hospital, \\ Capital MedicalUniversity, Xi-Cheng District, Beijing, P.R. China
}

\begin{abstract}
Background: The Ki67 index is a biomarker of proliferation, while the circulating tumor cell (CTC) count acts as a metastasis-related biomarker. In this study, we analyzed the potential value of CTC count and Ki67 index in diagnosis of colorectal cancer (CRC). Materials and Methods: A total of 105 patients with CRC undergoing surgery were included in the study. Isolation and identification of CTCs were performed by negative enrichment and immuno-fluorescence in situ hybridization, respectively. Expression of Ki67 was assessed by immunohistochemistry. Results: Patients with CTC count $\geq 2$ were defined as CTC-positive. Ki67 index $\geq 50 \%$ was regarded as highly proliferative. Overall, 71 cases were CTC-positive, while 82 cases displayed a high Ki67 index. CTC count and Ki67 index had no correlation with tumor size, tumor site, age, gender and TNM stages of the patients. CTC count was correlated with tumor size $(p=0.018)$ and Ki67 index with level of differentiation $(p<0.001)$. However, there was no relationship between CTC count and Ki67 index ( $p=0.198$ ). Conclusion: Our results suggest that CTCs can act as a potent metastasis-related biomarker for the diagnosis of CRC, independently of the Ki67 index.
\end{abstract}

According to estimates of the worldwide cancer incidence and mortality available from the 2012 GLOBOCAN report, colorectal cancer (CRC) has become the third and the second

Correspondence to: Zhongtao Zhang. Department of General Surgery, Beijing Key Laboratory of Cancer Invasion and Metastasis Research \& National Clinical Research Center for Digestive Diseases, Beijing Friendship Hospital, Capital Medical University, 95 Yong-an Road, Xi-Cheng District, Beijing 100050, P.R. China. E-mail: zhongtaozt@hotmail.com

Key Words: Colorectal cancer, diagnosis, circulating tumor cells, Ki67 index. most common type of cancer in men and in women respectively, and reported to be the fourth leading cause of cancer-related death (1). Although there is a broad geographic variation in the incidence of CRC, it has been noted that almost $55 \%$ of CRC cases occur in more highly developed regions. In China, $\mathrm{CRC}$ is also a relatively common type of cancer, with an annual incidence rate significantly growing since 1998. There is also a tendency towards an increase in younger patients (2-4).

Patients diagnosed with early-stage CRC usually undergo recommended surgical tumor resection, yet $20-30 \%$ of these patients may suffer from recurrence or metastasis within 5 years after surgery (5-7). A number of reasons may contribute to this discrepancy of survival. One is that tumor cells may be present in the circulation. These viable cancer cells with potent proliferative and metastatic capacity may have been shed into the bloodstream from the primary tumor site before or even during surgical resection, and then these cells (socalled circulating tumor cells, CTCs) travel throughout the body through the systemic circulation $(8,9)$. Accordingly, they constitute the seeds for subsequent growth of additional tumors, causing relapse of cancer in these patients $(10,11)$. As a matter of fact, CTCs are a heterogeneous population of cells bearing diverse biological features, and they are often distinguished from their respective primary counterparts (12). Taking advantage of these features, characterization of CTCs at different time points during cancer progression is considered to provide useful information for diagnosis, evaluation of prognosis and decision making of therapeutic strategies $(13,14)$. In 2014 , Romiti et al. showed that the presence of CTCs is negatively associated with the survival of patients with CRC (15). Subsequently, Tsai et al. pointed out that the CTC count can serve as a prognostic marker for distant metastasis of CRC (16). Collectively, the quantity and activity of CTCs derived from the peripheral blood of patients with CRC can act as a cell-based biomarker with diagnostic and prognostic potential. 
Indeed, precise diagnosis of $\mathrm{CRC}$ requires a combination of multiple factors. Apart from cell-based biomarkers, various molecular biomarkers that enable detection of CRC at the early stage or evaluation of the progression and prognosis of such diseases have been identified (17-19). Among these molecules, the nuclear protein Ki67 has been recognized as a potent diagnostic target of various cancer types, including CRC. Previous investigations have suggested Ki67 contributes to enhanced proliferative activity of intrinsic cell populations in malignant tumors (20, 21). Accordingly, Ki67 has been suggested as a biomarker of tumor aggressiveness that can be applied in routine clinical practice (22-25). In light of its clinical significance, the Ki67 labeling index, which is based on immunohistochemistry (IHC), has been widely used as a diagnostic approach for assessing a number of tumor types (26).

The aim of the present study was to evaluate the potential of the CTC count and Ki67 index in the diagnosis of CRC and determine whether their utility is correlated with patient gender and age, tumor size and site, tumor stage and differentiation level. In particular, we analyzed whether the CTC count and Ki67 index are mutually correlated and could be used as a more accurate and precise diagnostic tool when combined.

\section{Materials and Methods}

Patients. One hundred and five patients were randomly selected, between April 2015 and August 2016, from patients who were diagnosed with CRC and underwent pathological examination at the Department of General Surgery, Beijing Friendship Hospital, Capital Medical University. The human study protocol of the present study was reviewed and approved by the Research Ethics Committee of Beijing Friendship Hospital (The Beijing Health System Talents Plan Fund No 2016-P2-072-02). All of the eligible patients were informed of the essentials of this study, and gave their written consent before enrolment onto this study.

Blood sampling and enrichment of CTCs. Venous blood $(3.2 \mathrm{ml})$ was collected from the patients via BD Vacutainer Glass Blood Collection Tubes with Acid Citrate Dextrose (Becton, Dickinson and Company, Franklin Lakes, NJ, USA). In order to avoid contamination of epithelial cells, all samples were collected after discarding the first $2 \mathrm{ml}$ of blood. The blood samples were subject to centrifugation at $650 \times g$ at room temperature, after which the upper serum layer was discarded and the remaining cells resuspended in a lysis buffer solution. After $8 \mathrm{~min}$ of vertical mixing $(20 \mathrm{rpm})$ that facilitated lysis of red blood cells, the sample was subjected to centrifugation at $650 \times g$ at room temperature. The residual cell pellet was resuspended in phosphate buffer solution and subsequently incubated with anti-CD45 monoclonal antibody-coated magnetic beads for $30 \mathrm{~min}$, followed by the separation of magnetic beads using a magnetic stand (Promega, Madison, WI, USA). Afterwards, the samples were centrifuged at $800 \times g$ for $3 \mathrm{~min}$. Cell pellets were spotted on glass slides, and then immuno-fluorescence in situ hybridization (imFISH) staining was carried out.
imFISH staining. The enriched CTCs were subjected to imFISH analysis (27), which was performed using centromere DNA probes of chromosome 7 (green) and 8 (orange) centromere probes (Abbott Molecular Diagnostics, Des Plaines, IL, USA). The immunofluorescence assay was carried out using anti-CD45 (red). The glass slides were washed with Tris-buffered saline three times, before mounting. Cells were mounted with mounting medium containing the nuclear dye 4',6-diamidino-2-phenylindole (DAPI) and then visualized under a fluorescence microscope. Evaluation criteria for CTC identification included both chromosome enumeration probe $7 / 8 \geq 3$ and CD45- staining pattern overlying the DAPI staining of the nucleus. A CTC count of 2 or more was considered positive.

Ki67 IHC. Polypectomy specimens excised from the patients were subjected to formalin-fixed paraffin-embedded sectioning and then stained with the antibody to Ki67 and counterstained with hematoxylin and eosin. Biotin avidin alkaline phosphataseconjugated anti-goat IgG polyclonal antibodies (Maxvision ${ }^{\mathrm{TM}} 2 \mathrm{Kit}$; Maixin Biotech., Fuzhou, Fujian, China) was used as the secondary antibody for detection. Only unequivocal nuclear staining, regardless of its intensity, was counted. By definition, the fraction of cells positively staining with anti-Ki67 is designated as the Ki67 fraction or index.

Statistical analysis. All data were analyzed by Mann-Whitney, Kruskal-Wallis, Pearson chi-square and Spearman test. Pearson and Spearman correlation coefficient was used to measure the linear relationship with respect to the distribution of patient CTC counts among different Ki67 indices. A value of $p<0.05$ was considered statistically significant. All statistical analyses were performed using SPSS version 13.0 statistical software (SPSS, Chicago, IL, USA).

\section{Results}

Patient demographics. Among the 105 patients, 58 cases were males, while 47 cases were females; their ages ranged from 33 to 86 years, with a median age of 64 years. Regarding the tumor location, 22 cases were diagnosed with right-sided colon cancer, 36 cases with left-sided colon cancer, 38 cases with rectal cancer and nine cases simultaneous with colon and rectal cancer. According to the Tumor-Node-Metastasis (TNM) classification of malignant tumors published by the Union for International Cancer Control (AJCC/UICC 2010), an overall TNM stage of these patients was assigned, resulting in 11 cases of stage I, 39 cases of stage II, 47 cases of stage III, and 8 cases of stage $\mathrm{IV}$; regarding the $\mathrm{T}, \mathrm{N}$ and $\mathrm{M}$ staging systems, 14 and 91 patients were separately categorized into cases of stages $\mathrm{T} 1$ T2 and stages T3-T4, 49 and 56 patients were classified into cases of stage N0 and stages N1-N3 respectively, while 98 and seven patients were cases of stage M0 and stage M1, respectively. With respect to the tumor size, 40 patients were found to have tumor mass $5 \mathrm{~cm}$ or more in diameter, whereas 65 patients were found to have tumor mass smaller than $5 \mathrm{~cm}$. Cytological examination of the tumor differentiation grade showed that 10, 86 and nine patients had poor-grade, moderate-grade and high-grade tumors respectively. 
Yang et al: Simultaneous Use of Ki67 Index and CTC Count as Biomarkers of CRC

Table I. The correlation of circulating tumor cell (CTC) count with general characteristics of the 105 patients.

\begin{tabular}{|c|c|c|c|c|c|c|c|c|}
\hline \multirow[t]{2}{*}{ Characteristic } & \multirow{2}{*}{$\begin{array}{c}\text { Cases } \\
(\mathrm{N}=105)\end{array}$} & \multicolumn{3}{|c|}{ CTC count, $\mathrm{n}$} & \multirow[t]{2}{*}{$p$-Value } & \multicolumn{2}{|c|}{ CTC, n (\%) } & \multirow[t]{2}{*}{$p$-Value } \\
\hline & & $2(n=34)$ & $2-4(n=45)$ & $\geq 5(\mathrm{n}=26)$ & & Negative $(n=34)$ & Positive $(\mathrm{n}=71)$ & \\
\hline Gender & & & & & 0.860 & & & 0.609 \\
\hline Male & 58 & 20 & 23 & 15 & & $20(34.5)$ & $38(65.5)$ & \\
\hline Female & 47 & 14 & 22 & 11 & & $14(29.8)$ & $33(70.2)$ & \\
\hline Age & & & & & 0.292 & & & 0.554 \\
\hline$\leq 60$ Years & 39 & 14 & 18 & 7 & & $14(35.9)$ & $25(64.1)$ & \\
\hline$>60$ Years & 66 & 20 & 27 & 19 & & $20(30.3)$ & $46(69.7)$ & \\
\hline Tumor site & & & & & 0.525 & & & 0.356 \\
\hline Right-sided colon & 22 & 8 & 9 & 5 & & $8(36.4)$ & $14(63.6)$ & \\
\hline Left-sided colon & 36 & 10 & 17 & 9 & & $10(27.8)$ & $26(72.2)$ & \\
\hline Rectum & 38 & 15 & 14 & 9 & & $15(39.5)$ & $23(60.5)$ & \\
\hline Colon and rectum & 9 & 1 & 5 & 3 & & $1(11.1)$ & $8(88.9)$ & \\
\hline
\end{tabular}

CTC count and its association with patient status and pathological features. Thirty-four of the patients were found to have a CTC count of less than 2, whereas 45 and 26 case had counts ranging between 2 and 4 , and 5 or more, respectively. In this study, we used a count of 2 CTCs as a cut-off, which was to say that those with a CTC count equivalent to or greater than this cutoff were considered CTC-positive. Therefore, a total of 71 cases $(67.6 \%$ of the patients) were recognized as CTC-positive. As shown in Tables I and II, the proportion of CTC-positive patients, regardless of stratification by gender and age, tumor site and size, and tumor staging and differentiation, was much greater than those of CTC-negative patients. Notably, CTC-positivity was particularly high in patients with M1 stage disease with lymph node metastasis $(100 \%)$. There was significant association between CTC count and tumor size by the Mann-Whitney test $(p=0.018)$. However, the correlation analyses showed no significant differences in distribution of CTC-positive patients or CTC count with respect to any of the other studied demographic parameters by the MannWhitney, Kruskal-Wallis or Pearson chi-square test.

Ki67 index and its association with patient status and pathological features. According to the results of IHC analysis, we separated the patients into three Ki67 index groups, including 23 cases with indices less than 50\%, 51 cases with indices between 50 and $69 \%$, and 31 cases with $70 \%$ or more. By definition, tumors exhibiting a Ki67 index of $50 \%$ or more were considered to be highly proliferative. Based on this cutoff criterion, 82 out of the 105 patients were shown to have tumors displaying highly proliferative potential. As shown in Tables III and IV, the proportion of patients with a high Ki67 index (above 50\%), whatever the stratification conditions (the only exception being tumor differentiation), were at least two- to three-fold greater than those with low Ki67 indices. Above all, patients both at stage IV and M1 stage were all shown to bear tumors with highly proliferative potential. Intriguingly, we found that a greater number of cases whose tumors were highly differentiated instead presented low Ki67 indices, suggesting that highly differentiated tumors are poorly proliferative. The results of correlation analysis showed that significant differences in the distribution of a high Ki67 index ( $\geq 50 \%$ ) merely existed between patients bearing tumors of high- or moderate-differentiation and those of poor differentiation. Furthermore, there was significant association between Ki67 index and the level of tumor differentiation by the Pearson chi-square test $(p<0.001)$.

Correlation between CTC count and Ki67 index of patients with $C R C$. Inferred from the above data, we argued both CTC count and Ki67 index could be potent biomarkers for diagnosis of CRC, even though patient gender and age, along with tumor site, and stage, were not relevant to these. Subsequently, we aimed to clarify whether a correlation between CTC count and the Ki67 index existed, that is, if mutual interference occurs when simultaneously applying these two biomarkers to diagnose CRC. Pearson chi-square test demonstrated that there was no significant difference when comparing the correlation between the CTC count and the Ki67 index derived from these 105 patients $(p=0.198$, Table V). Figure 1A-C shows the distribution of the three CTC groups (i.e. CTC count $<2$, CTC count 2-4, and CTC count $\geq 5$ ) among a broader spectrum of Ki67 indices. Although we observed that the majority (over half) of the CTC-positive patients (CTC count >2) had Ki67 indices of between $50 \%$ and $69 \%$, linear fitting analysis $\left(\mathrm{R}^{2}=0.0083\right.$, Figure 1D) demonstrated that there was no correlation between CTC count and Ki67 index. Taken together, these 
Table II. The correlation of circulating tumor cell (CTC) count with clinicopathological features of the 105 patients.

\begin{tabular}{|c|c|c|c|c|c|c|c|c|}
\hline \multirow{2}{*}{$\begin{array}{l}\text { Clinicopathological } \\
\text { feature }\end{array}$} & \multirow{2}{*}{$\begin{array}{c}\text { Cases } \\
(\mathrm{N}=105)\end{array}$} & \multicolumn{3}{|c|}{ CTC count, $\mathrm{n}$} & \multirow[t]{2}{*}{$p$-Value } & \multicolumn{2}{|c|}{ CTC, n (\%) } & \multirow[t]{2}{*}{$p$-Value } \\
\hline & & $<2(\mathrm{n}=34)$ & $2-4(n=45)$ & $\geq 5(\mathrm{n}=26)$ & & Negative $(n=34)$ & Positive $(\mathrm{n}=71)$ & \\
\hline Tumor size & & & & & 0.018 & & & 0.082 \\
\hline$<5 \mathrm{~cm}$ & 65 & 17 & 27 & 21 & & $17(26.2)$ & $48(73.8)$ & \\
\hline$\geq 5 \mathrm{~cm}$ & 40 & 17 & 18 & 5 & & $17(42.5)$ & $23(57.5)$ & \\
\hline \multicolumn{9}{|l|}{ T-Staging } \\
\hline T1-2 & 14 & 3 & 6 & 5 & 0.246 & $3(21.4)$ & 11 (78.6) & 0.541 \\
\hline $\mathrm{T} 3-4$ & 91 & 31 & 39 & 21 & & $31(34.0)$ & $60(66.0)$ & \\
\hline $\mathrm{N}$-Staging & & & & & 0.775 & & & 0.717 \\
\hline No & 49 & 15 & 24 & 10 & & $15(30.6)$ & $34(69.4)$ & \\
\hline $\mathrm{N} 1-3$ & 56 & 19 & 21 & 16 & & $19(34.0)$ & $37(66.0)$ & \\
\hline M-Staging & & & & & 0.064 & & & 0.093 \\
\hline M0 & 98 & 34 & 41 & 23 & & $34(35.0)$ & $64(65.0)$ & \\
\hline M1 & 7 & 0 & 4 & 3 & & $0(0.0)$ & $7(100.0)$ & \\
\hline UICC staging & & & & & 0.597 & & & 0.554 \\
\hline I & 11 & 3 & 5 & 3 & & $3(27.3)$ & $8(72.7)$ & \\
\hline II & 39 & 12 & 20 & 7 & & $12(30.8)$ & $27(69.2)$ & \\
\hline III & 47 & 18 & 16 & 13 & & $18(38.3)$ & $29(61.7)$ & \\
\hline IV & 8 & 1 & 4 & 3 & & $1(12.5)$ & $7(87.5)$ & \\
\hline Tumor differentiation & & & & & 0.712 & & & 0.787 \\
\hline Poor & 10 & 2 & 8 & 0 & & $2(20.0)$ & $8(80.0)$ & \\
\hline Moderate & 86 & 29 & 35 & 22 & & $29(33.7)$ & $57(66.3)$ & \\
\hline High & 9 & 3 & 2 & 4 & & $3(33.3)$ & $6(66.7)$ & \\
\hline
\end{tabular}

UICC: Union for International Cancer Control.

Table III. The correlation of Ki67 index with general characteristics of the 105 patients.

\begin{tabular}{|c|c|c|c|c|c|c|c|c|}
\hline \multirow[t]{2}{*}{ Characteristic } & \multirow{2}{*}{$\begin{array}{c}\text { Cases } \\
(\mathrm{N}=105), \mathrm{n}\end{array}$} & \multicolumn{3}{|c|}{ Ki67 index, $\mathrm{n}$} & \multirow[t]{2}{*}{$p$-Value } & \multicolumn{2}{|c|}{ Proliferation, n (\%) } & \multirow[t]{2}{*}{$p$-Value } \\
\hline & & $\begin{array}{l}<50 \% \\
(\mathrm{n}=23)\end{array}$ & $\begin{array}{c}50-69 \% \\
(\mathrm{n}=51)\end{array}$ & $\begin{array}{l}\geq 70 \% \\
(\mathrm{n}=31)\end{array}$ & & Low $(n=23)$ & $\operatorname{High}(\mathrm{n}=82)$ & \\
\hline Gender & & & & & 0.817 & & & 0.276 \\
\hline Male & 58 & 15 & 23 & 20 & & $15(25.9)$ & $43(74.1)$ & \\
\hline Female & 47 & 8 & 28 & 11 & & $8(17.0)$ & $39(83.0)$ & \\
\hline Age & & & & & 0.579 & & & 0.451 \\
\hline$\leq 60$ Years & 39 & 7 & 20 & 12 & & $7(18.0)$ & $32(82.0)$ & \\
\hline$>60$ Years & 66 & 16 & 31 & 19 & & $16(24.2)$ & $50(75.8)$ & \\
\hline Tumor site & & & & & 0.629 & & & 0.928 \\
\hline Right-sided colon & 22 & 5 & 11 & 6 & & $5(22.7)$ & $17(77.3)$ & \\
\hline Left-sided colon & 36 & 9 & 19 & 8 & & $9(25.0)$ & $27(75.0)$ & \\
\hline Rectum & 38 & 7 & 18 & 13 & & $7(18.4)$ & $31(81.6)$ & \\
\hline Colon and rectum & 9 & 2 & 3 & 4 & & $2(22.2)$ & $7(77.8)$ & \\
\hline
\end{tabular}

results suggest that CTC count and Ki67 index are mutually independent when used as biomarkers for diagnosis of CRC.

\section{Discussion}

CRC, which usually develops in the lining of the colon (large intestine) or rectum, is one of the leading causes of cancer-related death. It has been noted that most CRCs begin as a benign or non-cancerous form called a polyp. If polyps are detected at an early stage and excised, CRC can be efficiently prevented (28). Since patient survival is highly dependent on the tumor stage at the time of diagnosis, it is important to precisely identify CRC at an early stage. By and large, the screening approaches currently applied to clinical 
Table IV. The correlation of Ki67 index with pathological features of the 105 patients.

\begin{tabular}{|c|c|c|c|c|c|c|c|c|}
\hline \multirow[t]{2}{*}{ Characteristic } & \multirow{2}{*}{$\begin{array}{c}\text { Cases } \\
(\mathrm{N}=105)\end{array}$} & \multicolumn{3}{|c|}{ Ki67 index, $\mathrm{n}$} & \multirow[t]{2}{*}{$p$-Value } & \multicolumn{2}{|c|}{ Proliferation, n (\%) } & \multirow[t]{2}{*}{$p$-Value } \\
\hline & & $\begin{array}{l}<50 \% \\
(\mathrm{n}=23)\end{array}$ & $\begin{array}{c}50-69 \% \\
(\mathrm{n}=51)\end{array}$ & $\begin{array}{l}\geq 70 \% \\
(\mathrm{n}=31)\end{array}$ & & Low $(\mathrm{n}=23)$ & $\operatorname{High}(\mathrm{n}=82)$ & \\
\hline Tumor size & & & & & 0.562 & & & 0.908 \\
\hline$<5 \mathrm{~cm}$ & 65 & 14 & 34 & 17 & & $14(21.5)$ & $51(78.5)$ & \\
\hline$\geq 5 \mathrm{~cm}$ & 40 & 9 & 17 & 14 & & $9(22.5)$ & $31(77.5)$ & \\
\hline T-Staging & & & & & 0.682 & & & 0.501 \\
\hline $\mathrm{T} 1-2$ & 14 & 4 & 6 & 4 & & $4(28.6)$ & $10(71.4)$ & \\
\hline $\mathrm{T} 3-4$ & 91 & 19 & 45 & 27 & & $19(20.9)$ & $72(79.1)$ & \\
\hline $\mathrm{N}$-Staging & & & & & 0.956 & & & 0.729 \\
\hline No & 49 & 10 & 25 & 14 & & $10(20.4)$ & $39(75.6)$ & \\
\hline $\mathrm{N} 1-3$ & 56 & 13 & 26 & 17 & & $13(23.2)$ & $43(76.8)$ & \\
\hline M-Staging & & & & & 0.856 & & & 0.343 \\
\hline M0 & 98 & 23 & 45 & 30 & & $23(23.5)$ & $75(76.5)$ & \\
\hline M1 & 7 & 0 & 6 & 1 & & $0(0.0)$ & $7(100.0)$ & \\
\hline UICC staging & & & & & 0.753 & & & 0.138 \\
\hline I & 11 & 4 & 4 & 3 & & $4(36.4)$ & 7 (63.6) & \\
\hline II & 39 & 6 & 22 & 11 & & $6(15.4)$ & $33(84.6)$ & \\
\hline III & 47 & 13 & 19 & 15 & & $13(27.7)$ & $34(72.3)$ & \\
\hline IV & 8 & 0 & 6 & 2 & & $0(0.0)$ & $8(100.0)$ & \\
\hline Tumor differentiation & & & & & 0.029 & & & $<0.001$ \\
\hline Poor & 10 & 1 & 6 & 3 & & $1(10.0)$ & $9(90.0)$ & \\
\hline Moderate & 86 & 15 & 45 & 26 & & $15(17.4)$ & $71(82.6)$ & \\
\hline High & 9 & 7 & 0 & 2 & & $7(77.8)$ & $2(22.2)$ & \\
\hline
\end{tabular}

UICC: Union for International Cancer Control.

Table V. The correlation between circulating tumor cell (CTC) count and Ki67 index.

\begin{tabular}{|c|c|c|c|c|c|c|c|c|}
\hline & & \multicolumn{3}{|c|}{ CTC count } & \multirow[b]{2}{*}{$p$-Value } & \multicolumn{2}{|c|}{ CTC count } & \multirow[b]{2}{*}{$p$-Value } \\
\hline & & $<2(\mathrm{n}=34)$ & $2-4(n=45)$ & $\geq 5(\mathrm{n}=26)$ & & Negative $(n=34)$ & Positive ( $\mathrm{n}=71$ ) & \\
\hline \multirow{5}{*}{ Ki67 index } & $<50 \%(\mathrm{n}=23)$ & 10 & 6 & 7 & \multirow{3}{*}{0.415} & 10 & 13 & \multirow{3}{*}{0.070} \\
\hline & $50-69 \%(\mathrm{n}=51)$ & 11 & 26 & 14 & & 11 & 40 & \\
\hline & $\geq 70 \%(\mathrm{n}=31)$ & 13 & 13 & 5 & & 13 & 18 & \\
\hline & Low proliferation $(n=23)$ & 10 & 6 & 7 & \multirow[t]{2}{*}{0.651} & 10 & 13 & \multirow[t]{2}{*}{0.198} \\
\hline & High proliferation $(n=82)$ & 24 & 39 & 19 & & 24 & 58 & \\
\hline
\end{tabular}

diagnosis of CRC is divided into semi-invasive procedures (e.g. colonoscopy) and non-invasive examination (e.g. fecal occult blood test) (28). Over the past two decades, various molecular biomarkers capable of detecting CRC at the early stage or evaluating the progression and prognosis of such diseases have been identified (17-19). Among these molecules, the nuclear protein $\mathrm{Ki} 67$ has been regarded as a promising diagnostic target of many cancer types, including CRC. Expression of Ki67 contributes to enhanced proliferative activity of intrinsic cell populations in malignant tumors, thus rendering a biomarker of tumor aggressiveness $(20,21)$. There is accumulating literature suggesting Ki67 to be an indicator of proliferation of individual tumors in routine clinical practice (22-25). In the light of its clinical significance, the Ki67 labeling index has been widely used as a diagnostic approach for assessing a number of tumor types (26). Recently, Li et al. suggested that a high Ki67 index can be regarded as an independent prognostic biomarker associated with clinicopathological features of patients with stage III and IV CRC (29).

In this study, we randomly collected 105 individuals from the patients diagnosed with CRC at our hospital. Their polyp biopsy specimens were subjected to IHC staining to acquire the Ki67 labeling index. Among these patients, 82 cases were 
determined as having highly-proliferative tumors (Ki67 index is greater than $50 \%$ ). Regardless of gender, age, tumor site, tumor size, and tumor staging, patients with CRC were generally shown to bear tumors displaying high Ki67 indices. However, with respect to tumor differentiation, our study showed that highly differentiated CRC appeared to be poorly proliferative, whereas poorly and moderately differentiated CRC appeared to be highly proliferative. These results make sense since malignant tumors are comprised of both cancer stem cells, which are poorly differentiated and have great proliferative potential, as well as more highly differentiated cancer cells, with limited proliferative capacity (30).

Precise detection of CRC requires a combination of multiple biomarkers. Apart from the protein-based biomarkers, CTCs have been regarded as a new tumor biomarker in 'liquid biopsy' and have been widely used in the diagnosis of colorectal cancer (12). CTC characterization at different time points during tumor progression may provide advantageous predictive information for selecting the most appropriate and effective treatment (13). In addition, CTC detection is correlated with disease stage, relapse rate and survival of patients with various cancer types (12). The CTC count can also provide information on biological activity and enable real-time prediction of the prognosis of patients with distant metastases (31-34). A recent study carried by Chen et al. identified epithelial cell transforming sequence 2 oncogene (ECT2) as a highly sensitive and specific marker of CTCs derived from the peripheral blood of patients with CRC (35). In this regard, measurement of the expression level of ECT2 can therefore serve as an alternative approach for diagnosis and monitoring of CRC.

In the present study, we determined the counts of CTCs isolated from the venous blood of 105 patients with CRC and evaluated whether they were correlated with gender, age, tumor site, tumor size, tumor stage, and differentiation level. Unsurprisingly, we found that a great majority of patients with CRC, regardless of stratification by any of the demographic factors, were shown to be CTC-positive, suggesting that the CTC count is a potent biomarker of CRC. In order to achieve diagnostic accuracy and precision, it would be better to combine the CTC count simultaneously with the Ki67 index in diagnosis of CRC. For this reason, we examined the correlation between CTC count and Ki67 index to evaluate if mutual interference exists which might contribute to misdiagnosis. Fortunately, our results showed that there is a non-linear relationship with respect to the distribution of the CTC counts among different Ki67 indices, suggesting they can independently serve as biomarkers for diagnosis of CRC when used simultaneously.

In conclusion, we confirmed the potential of the CTC count and Ki67 index as biomarkers for diagnosis of CRC, which is independent of patient gender and age, tumor size and site, and tumor progression. Intriguingly, the Ki67 index
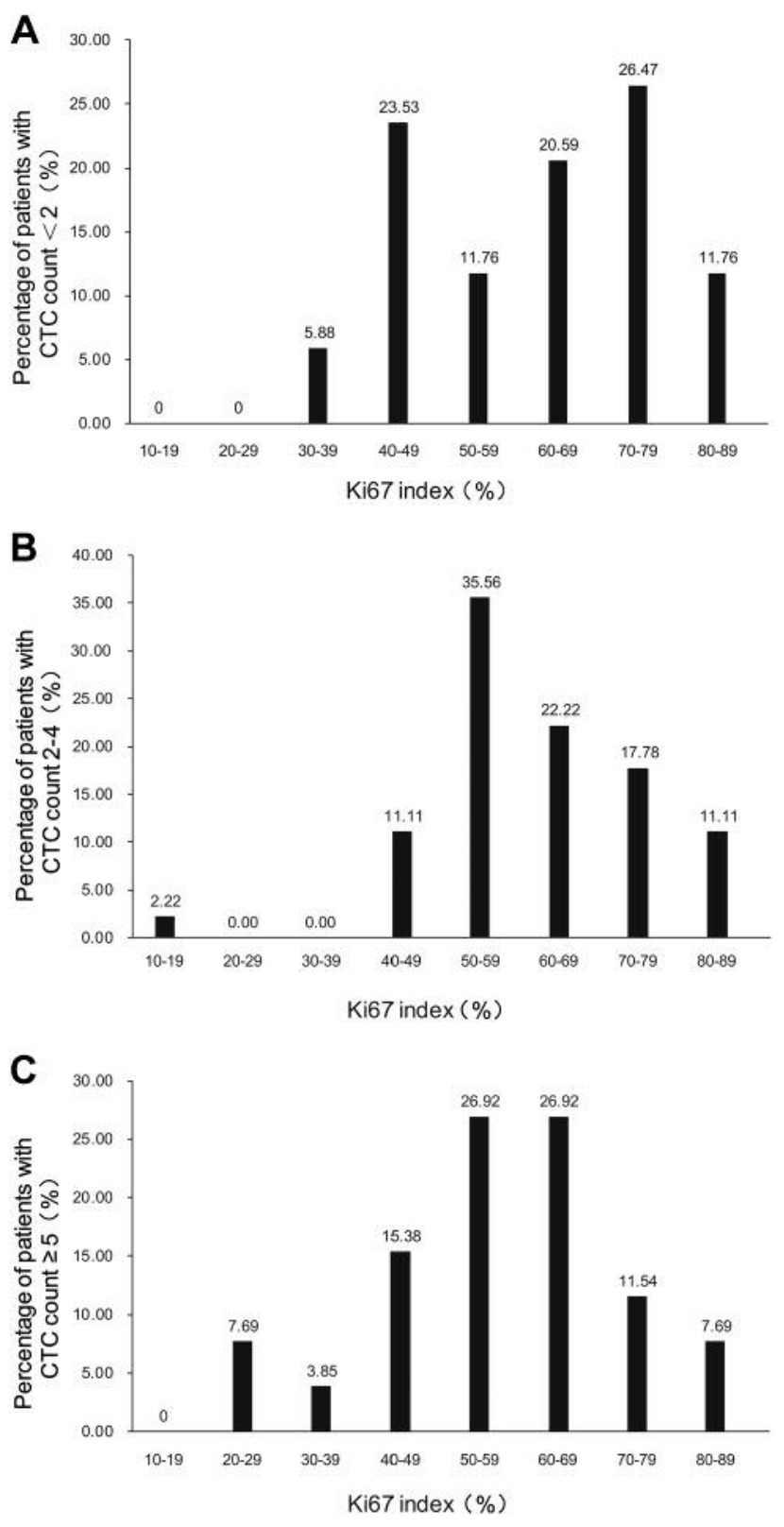

Figure 1. Continued.

was shown to be negatively associated with tumor differentiation. Moreover, the CTC count can also act as a metastasis-related biomarker of CRC, which is independent of the Ki67 index.

\section{Acknowledgments}

This study was supported by the financial grants from the Beijing Health System Talents Plan Fund (No 5th “215” 2016-P2-072-02). 


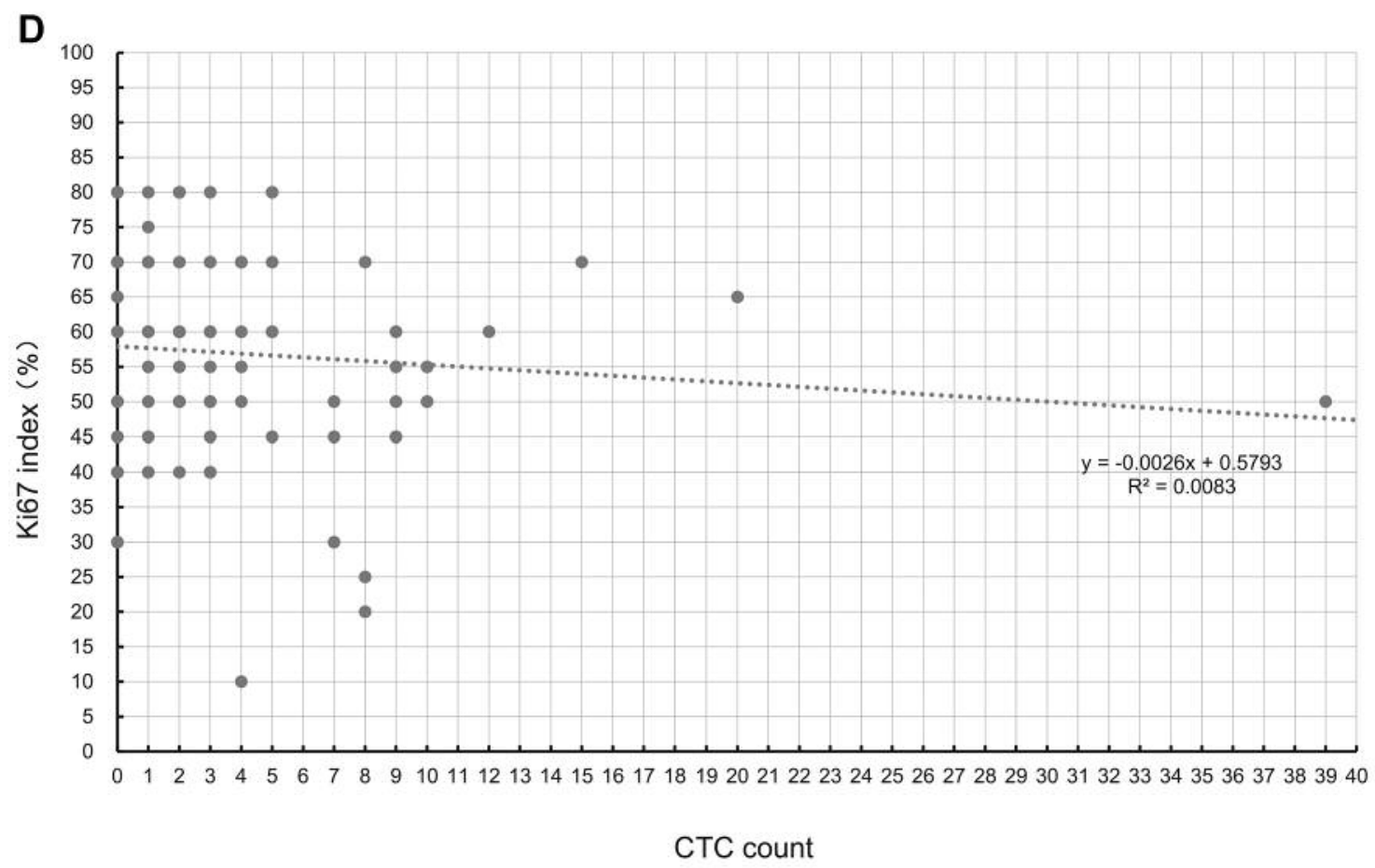

Figure 1. The distribution of patients with different circulating tumor cell (CTC) counts. CTC count of $<2$ (A), between 2 and 4 (B), and greater than 5 (C) among a wide spectrum of Ki67 indices. (D) Linear fitting analysis again proves no correlation between the CTC count and the Ki67 index derived from these 105 patients.

The Authors also thank Solomon Brothers Medical Technology Corporation for technical assistance.

\section{References}

1 Ferlay J, Soerjomataram I, Dikshit R, Eser S, Mathers C, Rebelo M, Parkin DM, Forman D and Bray F: Cancer incidence and mortality worldwide: sources, methods and major patterns in GLOBOCAN 2012. Int J Cancer 136(5): E359-386, 2015.

2 Torre LA, Bray F, Siegel RL, Ferlay J, Lortet-Tieulent J and Jemal A: Global cancer statistics, 2012. CA Cancer J Clinicians 65(2): 87-108, 2015.

3 Liu S, Zheng R, Zhang M, Zhang S, Sun X and Chen W: Incidence and mortality of colorectal cancer in China, 2011. Chin J Cancer Res 27(1): 22-28, 2015.

4 Li W, Zhang G, Wang HL and Wang L: Analysis of expression of cyclin E, p27kip1 and Ki67 protein in colorectal cancer tissues and its value for diagnosis, treatment and prognosis of disease. Eur Rev Med Pharmacol Sci 20(23): 4874-4879, 2016.

5 Smith JAE, King PM, Lane RHS and Thompson MR: Evidence of the effect of 'specialization' on the management, surgical outcome and survival from colorectal cancer in Wessex. Br J Surg 90(5): 583-592, 2003.

6 West NP, Hohenberger W, Weber K, Perrakis A, Finan PJ and Quirke P: Complete mesocolic excision with central vascular ligation produces an oncologically superior specimen compared with standard surgery for carcinoma of the colon. J Clin Oncol 28(2): 272-278, 2009.

7 Ryuk JP, Choi, GS, Park JS, Kim HJ, Park SY, Yoon, GS and Kwon YC: Predictive factors and the prognosis of recurrence of colorectal cancer within 2 years after curative resection. Ann Surg Treat Res 86(3): 143-151, 2014.

8 Ashworth TR: A case of cancer in which cells similar to those in the tumours were seen in the blood after death. Aust Med J 14(3): 146-149, 1869.

9 Klein CA: The metastasis cascade. Science 321(5897): 17851787, 2008.

10 Hardingham JE, Grover P, Winter M, Hewett PJ, Price TJ and Thierry B: Detection and clinical significance of circulating tumor cells in colorectal cancer -20 years of progress. Mol Med 21(Suppl 1): S25-31, 2015.

11 Dive C and Brady G: SnapShot: circulating tumor cells. Cell 168(4): 742-742, 2017.

12 Huang MY, Tsai HL, Huang JJ and Wang JY: Clinical implications and future perspectives of circulating tumor cells and biomarkers in clinical outcomes of colorectal cancer. Transl Oncol 9(4): 340-347, 2016.

13 Wang H-M, Lin S-R, Uen Y-H and Wang J-Y: Molecular detection of circulating tumor cells in colorectal cancer patients: from laboratory investigation to clinical implication. Fooyin J Health Sciences 1: 2-10, 2009. 
14 Cabel L, Proudhon C, Gortais H, Loirat D, Coussy F, Pierga JY and Bidard FC: Circulating tumor cells: clinical validity and utility. Int J Clin Oncol 22(3): 421-430, 2017.

15 Romiti A, Raffa S, Di Rocco R, Roberto M, Milano A, Zullo A, Leone L, Ranieri D, Mazzetta F, Medda E, Sarcina I, Barucca V, D'Antonio C, Durante V, Ferri M, Torrisi MR and Marchetti P: Circulating tumor cells count predicts survival in colorectal cancer patients. J Gastrointestin Liver Dis 23(3): 279-284, 2014.

16 Tsai WS, Chen JS, Shao HJ, Wu JC, Lai JM, Lu SH, Hung TF, Chiu YC, You JF, Hsieh PS, Yeh CY, Hung HY, Chiang SF, Lin GP, Tang R and Chang YC: Circulating tumor cell count correlates with colorectal neoplasm progression and is a prognostic marker for distant metastasis in non-metastatic patients. Sci Rep 6: 24517, 2016.

17 Lieu C and Kopetz S: The SRC family of protein tyrosine kinases: a new and promising target for colorectal cancer therapy. Clin Colorectal Cancer 9(2): 89-94, 2010.

18 Gonzalez-Pons $\mathrm{M}$ and Cruz-Correa $\mathrm{M}$ : Colorectal cancer biomarkers: Where are we now? Biomed Res Int 2015: 149014, 2015.

19 Newton KF, Newman W and Hill J: Review of biomarkers in colorectal cancer. Colorectal Dis 14(1): 3-17, 2012.

20 Kloppel G, Perren A and Heitz PU: The gastroenteropancreatic neuroendocrine cell system and its tumors: the WHO classification. Ann NY Acad Sci 1014: 13-27, 2004.

21 Brown DC and Gatter KC: Ki67 protein: The immaculate deception? Histopathology 40(1): 2-11, 2002.

22 Shibuya M, Ito S, Miwa T, Davis RL, Wilson CB and Hoshino T: Proliferative potential of brain tumors. Analyses with Ki-67 and anti-DNA polymerase alpha monoclonal antibodies, bromodeoxyuridine labeling, and nuclear organizer region counts. Cancer 71(1): 199-206, 1993.

23 Khan MS, Luong TV, Watkins J, Toumpanakis C, Caplin ME and Meyer T: A comparison of Ki-67 and mitotic count as prognostic markers for metastatic pancreatic and midgut neuroendocrine neoplasms. Br J Cancer 108(9): 1838-1845, 2013.

24 Rosati G, Chiacchio R, Reggiardo G, De Sanctis D and Manzione L: Thymidylate synthase expression, p53, BCL-2, Ki67 and p27 in colorectal cancer: relationships with tumor recurrence and survival. Tumour Biol 25(5-6): 258-263, 2004.

25 Xie S, Liu Y, Qiao X, Hua RX, Wang K, Shan XF and Cai ZG: What is the prognostic significance of Ki-67 positivity in oral squamous cell carcinoma? J Cancer 7(7): 758-767, 2016.
26 Li LT, Jiang G, Chen Q and Zheng JN: Ki67 is a promising molecular target in the diagnosis of cancer (review). Mol Med Rep 11(3): 1566-1572, 2015.

27 Li J, Wang Z, Chong T, Chen H, Li H, Li G, Zhai X and Li Y: Overexpression of a poor prognostic marker in prostate cancer: AQP5 promotes cells growth and local invasion. World J Surg Oncol 12: 284, 2014.

28 Das V, Kalita J and Pal M: Predictive and prognostic biomarkers in colorectal cancer: A systematic review of recent advances and challenges. Biomed Pharmacother 87: 8-19, 2017.

29 Li P, Xiao ZT, Braciak TA, Ou QJ, Chen G and Oduncu FS: Association between Ki67 index and clinicopathological features in colorectal cancer. Oncol Res Treat 39(11): 696-702, 2016.

30 Pardal R, Clarke MF and Morrison SJ: Applying the principles of stem-cell biology to cancer. Nat Rev Cancer 3(12): 895-902, 2003.

31 Cohen SJ, Punt CJ, Iannotti N, Saidman BH, Sabbath KD, Gabrail NY, Picus J, Morse M, Mitchell E, Miller MC, Doyle GV, Tissing H, Terstappen LW and Meropol NJ: Relationship of circulating tumor cells to tumor response, progression-free survival, and overall survival in patients with metastatic colorectal cancer. J Clin Oncol 26(19): 3213-3221, 2008.

32 de Bono JS, Scher HI, Montgomery RB, Parker C, Miller MC, Tissing H, Doyle GV,Terstappen LW, Pienta KJ and Raghavan D: Circulating tumor cells predict survival benefit from treatment in metastatic castration-resistant prostate cancer. Clin Cancer Res 14(19): 6302-6309, 2008.

33 Cristofanilli M: Circulating tumor cells, disease progression, and survival in metastatic breast cancer. Semin Oncol 33(3 Suppl 9): S9-14, 2006.

34 Shi J, Li Y, Liang S, Zeng J, Liu G, Mu F, Li H, Chen J, Liu T and Niu L: Analysis of circulating tumor cells in colorectal cancer liver metastasis patients before and after cryosurgery. Cancer Biol Ther 17(9): 935-942, 2016.

35 Chen CJ, Sung WW, Chen HC, Chern YJ, Hsu HT, Lin YM, Lin $\mathrm{SH}$, Peck K and Yeh KT: Early assessment of colorectal cancer by quantifying circulating tumor cells in peripheral blood: ECT2 in diagnosis of colorectal cancer. Int J Mol Sci 18(4): E743, 2017. 